\title{
AN INVESTOR'S PERSPECTIVE ON INFECTIOUS DISEASES AND THEIR INFLUENCE ON MARKET BEHAVIOR
}

\author{
Yi-Hsien Wang', Fu-Ju Yang², Li-Je Chen ${ }^{3}$ \\ ${ }^{1,2}$ Department of Banking and Finance, Chinese Culture University, Taiwan \\ ${ }^{3}$ Graduate Institute of International Business Administration, \\ Chinese Culture University, Taiwan \\ E-mail: ${ }^{1}$ holland@mail2000.com.tw (corresponding author) \\ Received 03 November 2011; accepted 09 July 2012
}

\begin{abstract}
Recently, increasing number of infectious diseases has swept the world. The outbreak of a contagious disease not only affects the health and lives of people but also causes economic growth to stagnate. Business in the biotechnology industry is closely related to infectious diseases but what exactly is the information value of the outbreak of infectious disease on biotechnology? This study investigates how such outbreaks can affect the performance of biotechnology stocks. In the past 10 years, major statutory infectious diseases in Taiwan have included ENTEROVIRUS 71, DENGUE FEVER, SARS and H1N1. The empirical results indicate that there is a significant abnormal return on company shares in Taiwan's biotechnology industry because of statutory infectious epidemics. The relationship between the financial ratios of biotechnology companies and abnormal returns was analyzed as part of this research. The results show that the influence on R\&D ratios, current ratios and assets are significant. Empirical findings reveal that the investors rationally measure operating conditions of the biotechnology companies during outbreaks of major infectious disease and adjust portfolio allocation accordingly.
\end{abstract}

Keywords: biotechnology industry, infectious diseases, investor's perspective, abnormal returns, stock performance, risk factor, market model.

Reference to this paper should be made as follows: Wang, Y.-H.; Yang, F.-J.; Chen, L.-J. 2013. An investor's perspective on infectious diseases and their influence on market behavior, Journal of Business Economics and Management 14(Supplement 1): S112-S127.

JEL Classification: G14.

\section{Introduction}

Biotechnology in the 21st century is a very active field. Many countries, including Taiwan, invest heavily in biotechnology industry. Biotechnology industry is a high-tech industry and its development requires the input of a lot of capital and technology (Hall, Bagchi-Sen 2002). As early as the 1990s, the Taiwanese government had already started to formulate industrial development strategies; as a result of incentives provided, many biotechnology companies were established. Because the establishment of new companies is very important to a country's economic health and capital markets, Taiwan's government hopes that these newly established biotech companies will promote economic competiveness (Hsu et al. 2005; Strandskov 2006). 
Taiwan's biotechnology industry can be divided into three major categories: pharmaceuticals, medical products, and other medical-related areas such as retail medical supplies. The operating revenue of the biotechnology industry amounted to NT 2,105 million in 2009; the greatest proportion was in medical products, where revenues reached NT 825 million. The pharmaceutical category accounted for NT 700 million. Aside from economic development, the biotechnology industry benefits of all mankind. In recent years, an increasing number of infectious life-threatening diseases swept the world. The goal of developments in biotechnology is to treat or prevent diseases, and reduce the social impact of infectious diseases. Pandemic infectious diseases can negatively impact the national economy and to neglect them may cause heavy financial losses (Mayer 2000; Zhang et al. 2009).

The SARS epidemic struck Asian countries in 2003 causing a significant drop in tourism in the region. Because of different levels of damage, the tourism industry in Asian countries was affected to different degrees by SARS (Page et al. 2006; Kuo et al. 2008). China was affected most; not only was tourism impacted but also retail sales, restaurants, hotels and the air transport industry (Keogh-Brown, Richard 2008). The SARS epidemic also affected the stock performance of many industries producing significantly negative cumulative abnormal returns in the chemicals, construction, department stores, food, hotels, textiles and automobile sectors in Taiwan (Chen et al. 2005; Chen et al. 2007; Chen 2011).

Whereas infectious diseases affect the stock performance of many industries do they also affect the stock performance of the biotechnology industry? As a disease spreads, demand for medicines, vaccines and related medical products tend to increase. As a result, major related $\mathrm{R} \& \mathrm{D}$ activities in biotechnological research within Asia may benefit (Wang et al. 2010). The biotechnology industry is committed to developing new products and producing economic rewards for the long term (Niosi 2003). Investors and shareholders are not myopic in their analysis of the true value of an emerging company (McMillan, Thomas 2005; Namara, Baden-Fuller 2007; Wang 2009; Ramchander et al. 2012). The outbreak of an infectious disease may be long or short term, but overall stock performance within the biotechnology industry is as yet unknown.

Specifically, the purpose of this paper is to investigate how the outbreak of infectious diseases affects stock performance within the biotechnology industry. According to the literature, there have been significant abnormal returns within Taiwan's biotechnology industry because of infectious epidemics (Yang et al. 2010). Along with the findings described by Yang et al. (2010), we have added more observations and used financial ratios to explain these abnormal returns. The rest of this paper is organized as follows. Section 1 describes data sources and the methodology. Section 2 discusses the empirical results and the last section concludes this paper.

\section{Methodology}

\subsection{Data source}

The data sources used for this study are: the prospectuses of Taiwanese listed companies on TSEC and OTC, the TEJ database and the UDN databases. ENTEROVIRUS 71, 
DENGUE FEVER, SARS and H1N1 were four specific infectious disease outbreaks in Taiwan within the past fifteen years. There are 75 observations belonging to 38 biotech companies.

The biotechnology industry is divided into three major categories: pharmaceuticals, medical products, and other medical-related products. There are 36 observations belonging to the pharmaceutical category, 29 observations belonging to the medical product category and 10 observations belonging to other medical-related categories, which include retail medical supplies, bio-cosmetics, health food and other medical-related business.

\subsection{Event study}

An event study is widely applied to determine whether there has been any information effect on the stock performance around the announcement date in different events (Davidson et al. 1987; Rajiv et al. 1993; Bradford, Robinson 1997; Patten, Nance 1998; Pantzalis et al. 2000; Chen, Su 2010; Lai et al. 2010; Ramiah et al. 2010; Chuang, Wang 2010; Asgharian et al. 2011; Cheung 2011; Li, Tallman 2011; Ramchander et al. 2012). Recent literature used event study to measure the effect of specific events, such as the effect of the Alaskan oil spill on the stock performance of petroleum companies and the effect of war on the stock performance of transportation companies. When the business of a company is affected by a specific event, either directly or indirectly, the result is significant abnormal returns (Epstein, Schnietz 2002; Chen 2005; Returns et al. 2007; Lin et al. 2008; Raghu et al. 2008; Chavis, Leslie 2009; Yanase, Yasuda 2010; Konchitchki, O’Leary 2011; Castañeda, Vargas 2012; Da Graca, Masson 2012).

Event study analysis has been applied to examine the relationship between the outbreak of an infectious disease and the stock performance of Taiwan's biotechnology industry. The announcement date for each disease is determined by the day of the first confirmed death case in Taiwan. The announcement date for ENTEROVIRUS 71 was May 27, 1998; for DENGUE FEVER it was July 14, 2002; for SARS it was April 27, 2003; and for H1N1 it was July 30, 2009. The event period is 31 trading days. The estimated period consists of 90 trading days prior to the event period. The expected return was derived using the market model and Ordinary Least Square (OLS), which is based on the following regression model:

$$
R_{i t}=\alpha_{i}+\beta_{i} R_{m t}+\varepsilon_{i t}
$$

When beta is estimated by ordinary least squares, it will result in the risk factor of a relatively infrequent stock being underestimated. Where there are relatively frequent stock transactions, the risk factor tends to be overestimated (Scholes, Williams 1977). The following formula is applied to adjust the risk factor:

$$
\hat{\beta}_{i}^{*}=\frac{\hat{\beta}_{i}^{-}+\hat{\beta}_{i}+\hat{\beta}_{i}^{+}}{1+2 \hat{\rho}_{m}} .
$$

$\hat{\beta}_{i}^{*}$ is the unbiased estimator beta coefficients of firm $I ; \hat{\beta}_{i}^{-}$is the estimators of return of firm $i$ and previous market return by ordinary least squares; $\hat{\beta}_{i}^{+}$is the estimators of 
return of firm $i$ and latter market return by ordinary least squares; and $\hat{\rho}_{m}$ is the autocorrelation coefficient of market rate of return.

The value of the intercept is estimated by least squares model based on Eq. (3):

$$
\hat{\alpha}_{i}^{*}=\bar{R}_{i}-\hat{\beta}_{i}^{*} \bar{R}_{m},
$$

$\bar{R}_{i}$ is average return of firm $i$ for the estimated period. $\bar{R}_{m}$ is average market rate of return.

Average abnormal returns (AR) of $t$ days can be calculated as:

$$
\overline{A R_{t}}=\frac{\sum_{i=1}^{t} A R_{i, t}}{N},
$$

where $t=-15,-14, \ldots, 0, \ldots, 14,15$, and $N$ is total observations.

Cumulative abnormal return (CAR) can be calculated as the abnormal return through $t$ days from $\tau_{1}$ accumulated to $\tau_{2},\left(-15 \leqq \tau_{1} \leqq \tau_{2} \leqq 15\right)$ based on Eq. (5):

$$
\operatorname{CAR}\left(\tau_{1}, \tau_{2}\right)=\frac{1}{N} \sum_{i=1}^{N} \sum_{t=\tau_{1}}^{\tau_{2}}\left(A R_{i t}\right),
$$

$\operatorname{CAR}\left(\tau_{1}, \tau_{2}\right)$ is the average abnormal return from event $\tau_{1}$ day cumulative to $\tau_{2}$ day, and $\left(\tau_{1}, \tau_{2}\right)$ is the event window. The $t$-test is applied to the estimated statistics. The $t$-statistic for $\overline{A R_{t}}$ is calculated as:

$\left.\operatorname{Var}\left(\overline{A R_{t}}\right)\right)$ is the variance of $\overline{A R_{t}}$.

$$
t\left(\overline{A R}_{t}\right)=\frac{\overline{A R_{t}}}{\sqrt{\operatorname{Var}\left(\overline{A R}_{t}\right)}} .
$$

The t-test statistic for the CAR is calculated as:

$$
t(C A R)=\frac{\operatorname{CAR}\left(\tau_{1}, \tau_{2}\right)}{\sqrt{\operatorname{Var}\left(\operatorname{CAR}\left(\tau_{1}, \tau_{2}\right)\right)}} .
$$

$\operatorname{Var}\left(\operatorname{CAR}\left(\tau_{1}, \tau_{2}\right)\right)$ is the variance of $\operatorname{CAR}\left(\tau_{1}, \tau_{2}\right)$.

\section{Empirical results}

\subsection{The results of all samples}

To test whether infectious diseases impact biotechnology stock performance, event study analysis is applied to examine the relationship between the date of infectious disease outbreak and the performance of Taiwanese biotechnology stocks. Table1 presents abnormal returns (AR) for biotechnology stocks. The empirical results show that there are significantly positive abnormal returns on days $-15,-12,-9,-8,-3,1,8$ and 15 . They are statistically significant at 0.01 levels on days $-15,-12,-9,-8,-3,1$ and 15 . They are statistically significant at 0.05 levels on day 8 .There are significantly negative abnormal returns on days $-14,-13,-7,-6,-4,3,6,11,12$ and 14 . They are statistically significant at 0.01 levels on days $-13,-7,-4,3,11,12$ and 14 . They are statistically significant at 0.05 levels on days -6 and 6 . They are statistically significant at 0.1 levels on day -14 . The abnormal return on announcement date (date 0 ) is not significant. 
Table 1. AR of biotechnology industry during the period of infectious diseases

\begin{tabular}{cccccccc}
\hline Event window & AR & $t$-test & & Event window & AR & $t$-test & \\
\hline-15 & 1.7596 & 5.1959 & $* * *$ & 1 & 0.9523 & 3.1052 & $* * *$ \\
-14 & -0.5131 & -1.6825 & $*$ & 2 & -0.4400 & -1.4446 & \\
-13 & -1.9147 & -5.5174 & $* * *$ & 3 & -2.0381 & -4.9559 & $* * *$ \\
-12 & 1.6952 & 5.6322 & $* * *$ & 4 & -0.6215 & -1.4511 & \\
-11 & 0.2873 & 1.0665 & & 5 & -0.0591 & -0.2147 & \\
-10 & -0.0871 & -0.3006 & & 6 & -0.4607 & -2.1957 & $* *$ \\
-9 & 1.6739 & 5.2637 & $* * *$ & 7 & -0.0357 & -0.1662 & \\
-8 & 0.8678 & 2.7689 & $* * *$ & 8 & 0.4114 & 1.9882 & $* *$ \\
-7 & -1.6104 & -4.7187 & $* * *$ & 9 & 0.0333 & 0.1529 & \\
-6 & -0.5390 & -2.1302 & $* *$ & 10 & -0.2722 & -1.5304 & \\
-5 & 0.3356 & 0.9220 & & 11 & -1.5548 & -7.3989 & $* * *$ \\
-4 & -0.8910 & -3.4128 & $* * *$ & 12 & -0.8274 & -2.7014 & $* * *$ \\
-3 & 1.0548 & 3.8269 & $* * *$ & 13 & 0.0641 & 0.3437 & \\
-2 & 0.4289 & 1.0493 & & 14 & -0.6959 & -2.9054 & $* * *$ \\
-1 & -0.2551 & -0.7978 & & 15 & 0.8750 & 2.8993 & $* * *$ \\
0 & 0.0983 & 0.2858 & & & & &
\end{tabular}

Notes: * Significant level $0.1 ; * *$ Significant level $0.05 ; * * *$ Significant level 0.01 .

Table 2 presents the cumulative abnormal returns (CAR) of biotechnology stocks. The empirical evidence found that there are significantly positive cumulative abnormal returns on days $-15,-14,-11,-10,-9,-8,-7,-6,-5,-3,-2,-1,0,1$ and 2 ; there are significantly positive cumulative abnormal returns at 0.01 level on days $-15,-14,-9$, $-8,1$ and 2 . They are statistically significant at 0.05 levels on days $-11,-7,-5,-3,-2$, -1 and 0 . They are statistically significant at 0.1 levels on days -10 and -6 . There are significantly negative cumulative abnormal returns on days $12,13,14$ and 15 . They are statistically significant at 0.05 levels on day 14 . They are statistically significant at 0.1 levels on days 12, 13 and 15. Investors think that the outbreak of infectious diseases may be favorable to biotechnology stock performance. But when infectious diseases continued to spread, biotechnology stock performance steadily worsened.

\subsection{Results of classified samples}

In order to test the robustness of the results, the Biotechnology industry is divided into three major categories: pharmaceuticals, medical products, and other medical-related products. Table 3 presents abnormal returns for pharmaceutical product stocks. Empirical results show that there were significantly positive abnormal returns on days $-15,-12,-9,-3,1$ and 15 . These were statistically significant at 0.01 levels on days $-15,-12$ and -9 . They were statistically significant at 0.05 levels on days -3 and 1 . 
Table 2. CAR of biotechnology industry during the period of infectious diseases

\begin{tabular}{cccccccc}
\hline Event window & CAR & $t$-test & & Event window & CAR & $t$-test & \\
\hline-15 & 1.7596 & 5.1959 & $* * *$ & 1 & 3.3434 & 2.9723 & $* * *$ \\
-14 & 1.2465 & 2.9564 & $* * *$ & 2 & 2.9033 & 2.7054 & $* * *$ \\
-13 & -0.6682 & -1.2509 & & 3 & 0.8653 & 0.8079 & \\
-12 & 1.0270 & 1.5176 & & 4 & 0.2438 & 0.2186 & \\
-11 & 1.3143 & 2.0185 & $* *$ & 5 & 0.1847 & 0.1694 & \\
-10 & 1.2273 & 1.6745 & $*$ & 6 & -0.2760 & -0.2397 & \\
-9 & 2.9011 & 3.4242 & $* * *$ & 7 & -0.3117 & -0.2723 & \\
-8 & 3.7689 & 4.0817 & $* * *$ & 8 & 0.0996 & 0.0891 & \\
-7 & 2.1585 & 2.4988 & $* *$ & 9 & 0.1329 & 0.1162 & \\
-6 & 1.6195 & 1.8860 & $*$ & 10 & -0.1392 & -0.1195 & \\
-5 & 1.9551 & 2.2369 & $* *$ & 11 & -1.6941 & -1.3750 & \\
-4 & 1.0642 & 1.1768 & & 12 & -2.5214 & -1.8580 & $*$ \\
-3 & 2.1190 & 2.1256 & $* *$ & 13 & -2.4573 & -1.8648 & $*$ \\
-2 & 2.5479 & 2.3583 & $* *$ & 14 & -3.1532 & -2.1909 & $* *$ \\
-1 & 2.2928 & 2.1098 & $* *$ & 15 & -2.2781 & -1.6501 & $*$ \\
0 & 2.3911 & 2.0936 & $* *$ & & & & \\
\hline
\end{tabular}

Notes: * Significant level 0.1 ; ** Significant level 0.05 ; *** Significant level 0.01 .

Table 3. Average AR of pharmaceutical during the period of infectious diseases

\begin{tabular}{cccccccc}
\hline Event window & AR & $t$-test & & Event window & AR & $t$-test & \\
\hline-15 & 1.7698 & 3.4963 & $* * *$ & 1 & 1.1341 & 2.3622 & $* *$ \\
-14 & -0.4402 & -1.0220 & & 2 & -0.8786 & -2.0077 & $* *$ \\
-13 & -1.3783 & -2.7689 & $* * *$ & 3 & -1.7712 & -2.8562 & $* * *$ \\
-12 & 1.7962 & 4.5583 & $* * *$ & 4 & -0.1020 & -0.1640 & \\
-11 & -0.2112 & -0.6254 & & 5 & 0.1082 & 0.2694 & \\
-10 & 0.1690 & 0.3816 & & 6 & -0.8123 & -2.3204 & $* *$ \\
-9 & 1.5672 & 3.5193 & $* * *$ & 7 & -0.1222 & -0.3629 & \\
-8 & 0.1374 & 0.3542 & & 8 & 0.3371 & 1.1041 & \\
-7 & -1.7028 & -3.7147 & $* * *$ & 9 & 0.3516 & 1.0430 & \\
-6 & -0.5846 & -1.7032 & $*$ & 10 & -0.1911 & -0.7391 & \\
-5 & 0.6878 & 1.1118 & & 11 & -1.4844 & -4.8909 & $* * *$ \\
-4 & -0.9685 & -2.6611 & $* * *$ & 12 & -0.5625 & -1.3272 & \\
-3 & 0.9373 & 2.5027 & $* *$ & 13 & 0.0780 & 0.2757 & \\
-2 & 0.6873 & 1.0567 & & 14 & -0.5745 & -1.9166 & $*$ \\
-1 & -0.6743 & -1.4451 & & 15 & 0.8094 & 1.8368 & $*$ \\
0 & -0.1855 & -0.4234 & & & & & \\
\hline
\end{tabular}

Notes: * Significant level $0.1 ; * *$ Significant level 0.05 ; ** Significant level 0.01 . 
They were statistically significant at 0.1 levels on day 15 . There were significantly negative abnormal returns on days $-13,-7,-6,-4,2,3,6$ and 11 . They are statistically significant at 0.01 levels on days $-13,-7,-4,3$ and 11 . They are statistically significant at 0.05 levels on days 2 and 6 . They are statistically significant at 0.1 levels on day -6 .

Table 4 presents cumulative abnormal returns for pharmaceutical product stocks. The empirical evidence found that there were significantly positive cumulative abnormal returns on days $-15,-14,-12,-9,-8$ and 1 . There were significantly positive cumulative abnormal returns at 0.01 levels on days -15 . They were statistically significant at 0.05 levels on days -9 and -8 . They were statistically significant at 0.1 levels on days $-14,-12$ and 1 . There were significantly negative cumulative abnormal returns on day 14 , and they were statistically significant at 0.1 levels. The pharmaceutical category displayed significantly positive cumulative abnormal returns before day 1 . There were significantly negative cumulative abnormal returns after day 6 . This result is consistent with the general results of the total observation.

Table 4. CAR of pharmaceutical during the period of infectious diseases

\begin{tabular}{cccccccc}
\hline Event window & CAR & $t$-test & & Event window & CAR & $t$-test \\
\hline-15 & 1.7698 & 3.4963 & $* * *$ & 1 & 2.7407 & 1.6902 & $*$ \\
-14 & 1.3295 & 1.9109 & $*$ & 2 & 1.8621 & 1.2716 \\
-13 & -0.0488 & -0.0606 & & 3 & 0.0909 & 0.0634 \\
-12 & 1.7474 & 1.6665 & $*$ & 4 & -0.0110 & -0.0079 \\
-11 & 1.5362 & 1.4792 & & 5 & 0.0972 & 0.0736 \\
-10 & 1.7053 & 1.4124 & & 6 & -0.7151 & -0.4736 \\
-9 & 3.2724 & 2.5672 & $* *$ & 7 & -0.8373 & -0.5689 \\
-8 & 3.4098 & 2.4425 & $* *$ & 8 & -0.5002 & -0.3668 \\
-7 & 1.7070 & 1.3203 & & 9 & -0.1486 & -0.1116 \\
-6 & 1.1225 & 0.8456 & & 10 & -0.3397 & -0.2425 \\
-5 & 1.8102 & 1.3700 & & 11 & -1.8242 & -1.2408 \\
-4 & 0.8417 & 0.6397 & & 12 & -2.3867 & -1.4408 \\
-3 & 1.7790 & 1.2409 & & 13 & -2.3087 & -1.4227 \\
-2 & 2.4663 & 1.5649 & & 14 & -2.8832 & -1.7383 \\
-1 & 1.7920 & 1.1060 & & 15 & -2.0738 & -1.2694 \\
0 & 1.6065 & 1.0017 & & & & \\
\hline$*$ & & & & & \\
\hline
\end{tabular}

Notes: * Significant level $0.1 ; * *$ Significant level 0.05 ; *** Significant level 0.01 .

Table 5 presents the abnormal returns attained by medical product stocks. The empirical results show that there were significantly positive abnormal returns on days $-15,-12$, $-11,-9,-8,-3$ and 15 . They were statistically significant at 0.01 levels on days -12 , -9 and -8 . They were statistically significant at 0.05 levels on days $-15,-3$ and 15 . 
They were statistically significant at 0.1 levels on day -11 .There were significantly negative abnormal returns on days $-13,-7,-4,3,4,11$ and 12 . They were statistically significant at 0.01 levels on days $-13,3$ and 11 . They were statistically significant at 0.05 levels on days $-7,-4$ and 4 . They were statistically significant at 0.1 levels on day 12 .

Table 5. Average AR of medical product during the period of infectious diseases

\begin{tabular}{cccccccc}
\hline Event window & AR & $t$-test & & Event window & AR & $t$-test & \\
\hline-15 & 1.3753 & 2.3978 & $* *$ & 1 & 0.8340 & 1.6053 & \\
-14 & -0.2483 & -0.5005 & & 2 & -0.2437 & -0.4885 & \\
-13 & -2.1570 & -3.7220 & $* * *$ & 3 & -2.4577 & -4.0233 & $* * *$ \\
-12 & 1.4749 & 2.5933 & $* * *$ & 4 & -1.4192 & -2.1139 & $* *$ \\
-11 & 0.8666 & 1.8189 & $*$ & 5 & -0.3736 & -0.9006 & \\
-10 & -0.4599 & -1.0489 & & 6 & 0.0124 & 0.0435 & \\
-9 & 1.6713 & 2.9825 & $* * *$ & 7 & 0.1796 & 0.5347 & \\
-8 & 1.5024 & 2.6786 & $* * *$ & 8 & 0.1882 & 0.7065 & \\
-7 & -1.2521 & -1.9746 & $* *$ & 9 & -0.1582 & -0.4860 & \\
-6 & -0.3920 & -0.8265 & & 10 & -0.4990 & -1.5633 & \\
-5 & 0.2237 & 0.4329 & & 11 & -1.5407 & -4.4067 & $* * *$ \\
-4 & -0.9421 & -2.1106 & $* *$ & 12 & -1.0278 & -1.9246 & $*$ \\
-3 & 1.2136 & 2.5509 & $* *$ & 13 & 0.1735 & 0.5825 & \\
-2 & 0.5887 & 0.9425 & & 14 & -0.7148 & -1.5480 & \\
-1 & 0.2610 & 0.4648 & & 15 & 1.1316 & 2.2302 & $* *$ \\
0 & 0.4413 & 0.6784 & & & & & \\
\hline$*$ Sign & & & & & & \\
\hline
\end{tabular}

Notes: * Significant level $0.1 ; * *$ Significant level 0.05 ; *** Significant level 0.01 .

Table 6 presents cumulative abnormal returns of medical product stocks. The empirical evidence found that there were significantly positive cumulative abnormal returns on days $-15,-14,-9,-8,-7,-6,-5,-3,-2,-1,0,1$ and 2 . There were significantly positive cumulative abnormal returns at 0.01 levels on day -8 . They were statistically significant at 0.05 levels on days $-15,-1,0,1$ and 2 . They were statistically significant at 0.1 levels on days $-14,-9,-7,-6,-5,-3$ and -2 . The medical product category displayed significantly positive cumulative abnormal returns before day 2 . They were significant from day -9 to day -5 and day -3 to day 2 . The outbreak of an infectious disease was favorable to stock performance within the medical product category during the event period.

Table 7 presents the abnormal returns of other medical-related product stocks. The empirical results show that there were significantly positive abnormal returns on days $-15,-12,-9,-8,1$ and 8 . They were statistically significant at 0.01 levels on days -15 , 
Table 6. CAR of medical product during the period of infectious diseases

\begin{tabular}{cccccccc}
\hline Event window & CAR & $t$-test & & Event window & CAR & $t$-test & \\
\hline-15 & 1.3753 & 2.3978 & $* *$ & 1 & 5.0011 & 2.5368 & $* *$ \\
-14 & 1.1270 & 1.8226 & $*$ & 2 & 4.7575 & 2.4022 & $* *$ \\
-13 & -1.0300 & -1.1807 & & 3 & 2.2997 & 1.1354 & \\
-12 & 0.4450 & 0.4153 & & 4 & 0.8805 & 0.4066 & \\
-11 & 1.3115 & 1.2897 & & 5 & 0.5069 & 0.2301 & \\
-10 & 0.8516 & 0.7639 & & 6 & 0.5193 & 0.2342 & \\
-9 & 2.5229 & 1.7332 & $*$ & 7 & 0.6989 & 0.3198 & \\
-8 & 4.0253 & 2.5955 & $* * *$ & 8 & 0.8871 & 0.4057 & \\
-7 & 2.7731 & 1.8761 & $*$ & 9 & 0.7289 & 0.3200 & \\
-6 & 2.3811 & 1.6889 & $*$ & 10 & 0.2300 & 0.1006 & \\
-5 & 2.6048 & 1.7805 & $*$ & 11 & -1.3107 & -0.5268 & \\
-4 & 1.6627 & 1.0569 & & 12 & -2.3385 & -0.8729 & \\
-3 & 2.8763 & 1.6630 & $*$ & 13 & -2.1651 & -0.8329 & \\
-2 & 3.4649 & 1.8529 & $*$ & 14 & -2.8798 & -0.9799 & \\
-1 & 3.7259 & 2.0152 & $* *$ & 15 & -1.7483 & -0.6238 & \\
0 & 4.1672 & 2.0251 & $* *$ & & & & \\
\hline
\end{tabular}

Notes: * Significant level $0.1 ; * *$ Significant level $0.05 ; * * *$ Significant level 0.01 .

Table 7. Average AR of other medical-related during the period of infectious diseases

\begin{tabular}{cccccccc}
\hline Event window & AR & $t$-test & & Event window & AR & $t$-test & \\
\hline-15 & 2.8373 & 4.8648 & $* * *$ & 1 & 0.6405 & 1.9436 & $*$ \\
-14 & -1.5431 & -1.7547 & $*$ & 2 & 0.5695 & 0.7398 & \\
-13 & -3.1430 & -3.9739 & $* * *$ & 3 & -1.7820 & -1.4150 & \\
-12 & 1.9703 & 2.8860 & $* * *$ & 4 & -0.1781 & -0.1455 & \\
-11 & 0.4023 & 0.5094 & & 5 & 0.2505 & 0.2785 & \\
-10 & 0.0722 & 0.0920 & & 6 & -0.5671 & -1.5133 & \\
-9 & 2.0654 & 2.6550 & $* * *$ & 7 & -0.3489 & -0.7546 & \\
-8 & 1.6567 & 1.9809 & $* *$ & 8 & 1.3259 & 1.7361 & $*$ \\
-7 & -2.3164 & -3.2363 & $* * *$ & 9 & -0.5574 & -1.0466 & \\
-6 & -0.8015 & -1.5895 & & 10 & 0.0939 & 0.3803 & \\
-5 & -0.6075 & -1.2075 & & 11 & -1.8492 & -3.2740 & $* * *$ \\
-4 & -0.4635 & -0.6384 & & 12 & -1.1995 & -1.4993 & \\
-3 & 1.0176 & 1.2473 & & 13 & -0.3029 & -0.6669 & \\
-2 & -0.9644 & -1.2322 & & 14 & -1.0783 & -1.8651 & $*$ \\
-1 & -0.2427 & -0.4787 & & 15 & 0.3677 & 0.5075 & \\
0 & 0.1252 & 0.1478 & & & & & \\
\hline
\end{tabular}

Notes: * Significant level $0.1 ; * *$ Significant level $0.05 ; * * *$ Significant level 0.01 . 
-12 and -9 . They were statistically significant at 0.05 levels on day -8 . They were statistically significant at 0.1 levels on days 1 and 8 . There were significantly negative abnormal returns on days $-14,-13,-7,11$ and 14 . They were statistically significant at 0.01 levels on days $-13,-7$ and 11 . They were statistically significant at 0.1 levels on days -14 and 14 .

Table 8 presents the cumulative abnormal returns of other medical-related stocks. The empirical evidence found that there were significantly positive cumulative abnormal returns on days $-15,-9$ and -8 . There were significantly positive cumulative abnormal returns at 0.01 levels on day -15 . They were statistically significant at 0.05 levels on day -8 . They were statistically significant at 0.1 levels on day -9 . The "other medicalrelated" category had only significantly positive cumulative abnormal returns. In summary, the outbreak of infectious diseases was favorable to stock performance in the "other medical-related" category during the event period. Overall, the results of the pharmaceutical product category displayed significantly positive cumulative abnormal returns before day 1 and significantly negative cumulative abnormal returns after day 6 . The other two categories had only significantly positive cumulative abnormal returns.

Table 8. CAR of other medical-related during the period of infectious diseases

\begin{tabular}{ccccccc}
\hline Event window & CAR & $t$-test & Event window & CAR & $t$-test \\
\hline-15 & 2.8373 & 4.8648 & $* * *$ & 1 & 0.7055 & 0.3385 \\
-14 & 1.2942 & 1.5164 & 2 & 1.2750 & 0.6558 \\
-13 & -1.8489 & -1.6068 & 3 & -0.5070 & -0.2606 \\
-12 & 0.1214 & 0.0841 & 4 & -0.6850 & -0.2648 \\
-11 & 0.5237 & 0.4107 & & 5 & -0.4345 & -0.1936 \\
-10 & 0.5960 & 0.5184 & & 6 & -1.0016 & -0.4420 \\
-9 & 2.6614 & 1.7576 & $*$ & 7 & -1.3505 & -0.5169 \\
-8 & 4.3182 & 2.3123 & $* *$ & 8 & -0.0246 & -0.0089 \\
-7 & 2.0018 & 1.2185 & & 9 & -0.5820 & -0.1950 \\
-6 & 1.2003 & 0.7497 & & 10 & -0.4881 & -0.1626 \\
-5 & 0.5928 & 0.3418 & & 11 & -2.3373 & -0.8603 \\
-4 & 0.1293 & 0.0679 & & 12 & -3.5368 & -1.1043 \\
-3 & 1.1469 & 0.5036 & & 13 & -3.8397 & -1.2797 \\
-2 & 0.1825 & 0.0836 & 14 & -4.9180 & -1.4901 \\
-1 & -0.0602 & -0.0307 & & 15 & -4.5504 & -1.5485 \\
0 & 0.0649 & 0.0311 & & & \\
\hline
\end{tabular}

Notes: * Significant level $0.1 ; * *$ Significant level 0.05 ; *** Significant level 0.01 . 


\subsection{Windows analysis and cross-sectional regression analyses}

As shown by the results described in the previous paragraphs, infectious diseases affect stock performance both positively and negatively. As we seek to further narrow the window of analysis, Table 9 presents cumulative abnormal returns separately over the event periods; the CAR over the event windows $(-10,10),(-9,9),(-8,8),(-7,7),(-6$, $6),(-5,5),(-4,4),(-3,3),(-2,2)$ and $(-1,1)$ are calculated. There are significantly negative cumulative abnormal returns of the period $(-8,8),(-7,7),(-6,6)$ and $(-4,4)$. Although stock performance within the biotechnology industry shows both significantly positive and negative cumulative abnormal returns within an event period, it was found there is a significantly negative cumulative abnormal return within 2 weeks of the announcement date such as period $(-8,8),(-7,7),(-6,6)$ and $(-4,4)$.

Table 9. Windows analysis of CAR

\begin{tabular}{llll}
\hline Interval & CAR & t-test & \\
\hline-10 to 10 & -1.4535 & -1.1078 & \\
-9 to 9 & -1.0943 & -0.8839 & \\
-8 to 8 & -2.8014 & -2.1433 & $* *$ \\
-7 to 7 & -4.0806 & -3.0499 & $* * *$ \\
-6 to 6 & -2.4345 & -2.1840 & $* *$ \\
-5 to 5 & -1.4348 & -1.4382 & $* *$ \\
-4 to 4 & -1.7113 & -1.9626 & \\
-3 to 3 & -0.1988 & 1.6657 & \\
-2 to 2 & 0.7843 & 1.2189 & \\
-1 to 1 & 0.7954 & 1.1369 &
\end{tabular}

Notes: * Significant level 0.1 ;* Significant level 0.05 ; *** Significant level 0.01 .

The abnormal returns were further analyzed according to the financial ratios of biotech companies. Gross profit margins, research and development expense ratios, current ratios and the firm scale were applied for factor analysis. Financial ratios of the company are from the financial statements of the year prior to the announcement date. The firm scale is estimated by the book value of assets. The assets data are changed into a natural logarithm. Table 10 presents a cross-sectional regression analysis of event windows $(-7,7)$ which often brings abnormal returns to biotechnology industries. Because event windows $(-7,7)$ are the most significant, they were chosen as the independent variable. The biotechnology industry share price responses were significantly affected by the research and development expense ratio, as well as current ratio and assets. The research and development expense ratio was significantly negative at 0.01 levels. Current ratio and assets are significantly positive at 0.1 levels. 
The higher research and development (R\&D) expense ratio for companies resulted in a negative effect. Investors care about the companies' long-term interests and the success of development will result in receiving substantial long-term benefits. Investors were more confident with companies with a higher R\&D expense ratio because they seemed to face a better future. The failure of $R \& D$ results in adverse consequences once again proved the importance of R\&D to biotechnology.

The higher current ratio of companies achieved the enhanced effect by the outbreak of infectious diseases. The higher current ratio represents better solvency in the short-term. However, biotechnology is a capital intensive industry and the biotechnology companies having higher current ratios achieve higher abnormal returns.

The higher assets of companies were achieved by the outbreak of infectious diseases and the larger companies experienced the greatest effect. Investors displayed less confidence in those companies when infectious diseases were actually spreading. Because large companies have larger scale, their resources can be controlled efficiently in an emergency environment.

Table 10. Cross-sectional regression analyses of factors affecting CAR

\begin{tabular}{lc}
\hline \multicolumn{1}{c}{ Variable } & Coefficient \\
\hline Constant & $-47.8592^{* *}$ \\
Gross profit margin & 0.1623 \\
R \&D expense ratio & $-1.4574 * * *$ \\
Current ratio & $0.0187 *$ \\
Assets & $6.8927 *$ \\
R-squared & 0.3836 \\
Adjusted R-squared & 0.3231 \\
F-statistic & $6.3481 * * *$ \\
\hline Notes: * Significant level $0.1 ; * *$ Significant level $0.05 ; * * *$ Significant level 0.01.
\end{tabular}

\section{Conclusions}

The development of the biotechnology industry has been vigorous in Taiwan during recent years. This paper investigated the outbreak of infectious diseases and how such events affect the stock performance of biotechnology companies. Observations were based upon the stock performance of thirty-eight listed Taiwanese companies. Observed events of major infectious disease outbreaks in the past ten years in Taiwan, included ENTEROVIRUS 71, DENGUE FEVER, SARS and H1N1.

The results show that the outbreak of infectious diseases significantly affects biotechnology stock performance. There were significantly positive cumulative abnormal returns before day 2. There were significantly negative cumulative abnormal returns after day 12. According to Yang et al. (2010), the results showed significantly positive cumula- 
tive abnormal returns before day 2 , but there were no significantly negative cumulative abnormal returns. The results of this paper are consistent with those of Yang et al. (2010) before day 2, but differ after day 2 since stock price indicates significantly positive cumulative abnormal returns before day 2 . In other words, investors think that the outbreak of infectious diseases is favorable to the stock performance of biotechnology companies. However, when infectious diseases appeared to be spreading, biotechnology stock performance worsened; this indicates that the event (the first confirmed death case) may change the judgments of investors and may explain why there were no significantly positive cumulative abnormal returns after day 2 ; significantly negative cumulative abnormal returns may even result.

The pharmaceutical category showed significantly positive cumulative abnormal returns before day 1 and significantly negative cumulative abnormal returns after day 6 . The other two categories only had significantly positive cumulative abnormal returns. When infectious diseases were continuously spreading, demand for medical products and consumables increased and investors expected those companies' operating revenues to increase significantly. In other words, the outbreak of infectious diseases was favorable to the stock performance of companies producing medical products and other medical-related products during the event period. It was not clear whether or not the outbreak of infectious diseases was favorable to stock performance of pharmaceutical category. Hence, when infectious diseases are continuously spreading, investors may consider the risk of holding stocks as too high and begin selling shares; stock prices began to adjust downward after day 4 .

Finally we further narrowed the window of analysis. We found significantly negative cumulative abnormal returns within 2 weeks of the announcement date. In addition, we analyzed the abnormal returns by financial ratios of biotechnology companies. The results indicate that a higher R\&D expense ratio for companies produced a negative effect as the result of an outbreak of an infectious disease. Higher current ratio and assets of companies resulted from the outbreak of infectious diseases. This information may be important for biotechnology management; if in the future top management encounters the same situation, they should sustain the confidence level of investors by reducing the uncertainty of stocks in the market.

Most of Taiwanese biotechnology industries are medium-sized enterprises, and their operating ability and capital turnover are usually not as good as the stability of largesized enterprises. Therefore, how to use the excess stock returns and financial statements information is an important part of risk prevention. From an investor's perspective, the results of this study reflect not only the operating conditions of the company, but also to reduce investment risks brought about by the investing information asymmetry.

\section{Acknowledgment}

We would like to thank the anonymous referees for helpful comments and suggestions, and Yi-Hsien Wang also would like to thank the National Science Council of Taiwan for financially supporting this research under Contract No. NSC 101-2410-H-034-005. 


\section{References}

Asgharian, H.; Holmfeldt, M.; Larson, M. 2011. An event study of price movements following realized jumps, Quantitative Finance 11(6): 933-946. http://dx.doi.org/10.1080/14697680903369518 Bradford, B. M.; Robinson, H. D. 1997. Abnormal returns, risk, and financial statement data: the case of the Iraqi invasion of Kuwait, Journal of Economics and Business 49(2): 193-204. http://dx.doi.org/10.1016/S0148-6195(97)81515-9

Castañeda, A.; Vargas, J. F. 2012. Sovereign risk and armed conflict: an event-study for Colombia, Defence and Peace Economics 23(2): 185-201.

http://dx.doi.org/10.1080/10242694.2011.597233

Chavis, L.; Leslie, P. 2009. Consumer boycotts: the impact of the Iraq war on French wine sales in the U.S., Quantitative Marketing and Economics 7(1): 37-67.

http://dx.doi.org/10.1007/s11129-008-9043-y

Chen, M. H. 2005. Japanese and Korean stock market reactions to the 2002 World Cup, PanPacific Management Review 8(1): 39-61.

Chen, M. H.; Kim, W. G.; Kim, H. J. 2005. The impact of macroeconomic and non-macroeconomic forces on hotel stock returns, International Journal of Hospitality Management 24(2): 243-258. http://dx.doi.org/10.1016/j.ijhm.2004.06.008

Chen, M. H.; Jang, S. C.; Kim, W. G. 2007. The impact of the SARS outbreak on Taiwanese hotel stock performance: an event-study approach, Hospitality Management 26(1): 200-212. http://dx.doi.org/10.1016/j.ijhm.2005.11.004

Chen, M. H. 2011. The response of hotel performance to international tourism development and crisis events, International Journal of Hospitality Management 30(1): 200-212.

http://dx.doi.org/10.1016/j.ijhm.2010.06.005

Chen, S. S.; Su, X. Q. 2010. Market reaction to entry timing of corporate capital investment announcement: evidence from announcement-period abnormal returns and analysts' earnings forecast revisions, Review of Pacific Basin Financial Markets and Policies 13(4): 495-515.

http://dx.doi.org/10.1142/S0219091510002049

Cheung, A. W. K. 2011. Do stock investors value corporate sustainability? Evidence from an event study, Journal of Business Ethics 99(2): 145-165.

http://dx.doi.org/10.1007/s10551-010-0646-3

Chuang, C. C.; Wang, Y. H. 2010. Electoral information in developed stock market: testing conditional heteosecdasticity in the market model, Applied Economics 42(9): 1125-1131.

http://dx.doi.org/10.1080/00036840701721117

Da Graca, T.; Masson, R. 2012. More power to you: properties of a more powerful event study methodology, Review of Accounting and Finance 11(2): 166-183.

http://dx.doi.org/10.1108/14757701211228200

Davidson, W. N.; Chandy, P. R.; Cross, M. 1987. Large losses, risk management and stock returns in the airline industry, Journal of Risk and Insurance 54(1): 162-172.

http://dx.doi.org/10.2307/252888

Epstein, M. J.; Schnietz, K. E. 2002. Measuring the cost of environmental and labor protests to globalization: an event study of the failed 1999 Seattle WTO talks, International Trade Journal 16(2): 129-160. http://dx.doi.org/10.1080/08853900252901396

Hall, L. A.; Bagchi-Sen, S. 2002. A study of R\&D, innovation, and business performance in the Canadian biotechnology industry, Technovation 22(4): 231-244.

http://dx.doi.org/10.1016/S0166-4972(01)00016-5

Hsu, Y. G.; Shyu, J. Z.; Tzeng, G. H. 2005. Policy tools on the formation of new biotechnology firms in Taiwan, Technovation 25(3): 281-292. http://dx.doi.org/10.1016/S0166-4972(03)00078-6 
Keogh-Brown, M. R.; Richard, D. S. 2008. The economic impact of SARS: how does the reality match the predictions?, Health Policy 88(1): 110-120.

http://dx.doi.org/10.1016/j.healthpol.2008.03.003

Konchitchki, Y.; O'Leary, D. E. 2011. Event study methodologies in information systems research, International Journal of Accounting Information Systems 12(2): 99-115.

http://dx.doi.org/10.1016/j.accinf.2011.01.002

Kuo, H. I.; Chen, W. C.; Ju, L. F.; Huang, B. W. 2008. Assessing impacts of SARS and Avian Flu on international tourism demand to Asia, Tourism Management 29(5): 917-928.

http://dx.doi.org/10.1016/j.tourman.2007.10.006

Lai, J. H.; Chang, S. C.; Chen, S. S. 2010. Is experience valuable in international strategic alliances?, Journal of International Management 16(3): 247-261.

http://dx.doi.org/10.1016/j.intman.2010.06.004

Li, S.; Tallman, S. 2011. MNC strategies, exogenous shocks, and performance outcomes, Strategic Management Journal 32(10): 1119-1127. http://dx.doi.org/10.1002/smj.918

Lin, C. T.; Wang, Y. H.; Lin, W. R. 2008. Information effect of top executive turnover: testing hybrid grey-market model, Journal of Grey System 20(1): 53-64.

Mayer, J. D. 2000. Geography, ecology and emerging infectious diseases, Social Science \& Medicine 50(7): 937-952. http://dx.doi.org/10.1016/S0277-9536(99)00346-9

McMillan, G. S.; Thomas, P. 2005. Financial success in biotechnology: company age versus company science, Technovation 25(5): 463-468. http://dx.doi.org/10.1016/j.technovation.2004.10.009

Namara, P. M.; Baden-Fuller, C. 2007. Shareholder returns and the exploration-exploitation dilemma: R\&D announcements by biotechnology firms, Research Policy 36(4): 548-565.

http://dx.doi.org/10.1016/j.respol.2007.02.012

Niosi, J. 2003. Alliances are not enough explaining rapid growth in biotechnology firms, Research Policy 32(5): 737-750. http://dx.doi.org/10.1016/S0048-7333(02)00083-5

Page, S.; Yeoman, I.; Munro, C.; Connell, J.; Walker, L. 2006. A case study of best practice- visit Scotland's prepared response to an influenza pandemic, Tourism Management 27(3): 361-393. http://dx.doi.org/10.1016/j.tourman.2006.01.001

Pantzalis, C.; Stangeland, D. A.; Turtle, H. J. 2000. Political elections and the resolution of uncertainty: the international evidence, Journal of Banking \& Finance 24(10): 1575-604.

http://dx.doi.org/10.1016/S0378-4266(99)00093-X

Patten, D. M.; Nance, J. R. 1998. Regulatory cost effects in a good news environment: the intraindustry reaction to the Alaskan oil spill, Journal of Accounting and Public Policy 17(4-5): 409-429. http://dx.doi.org/10.1016/S0278-4254(98)10007-8

Raghu, T. S.; Woo, W.; Mohan, S. B.; Rao, H. R. 2008. Market reaction to patent infringement litigations in the information technology industry, Information Systems Frontiers 10(1): 61-75. http://dx.doi.org/10.1007/s10796-007-9036-5

Rajiv, K.; Henderson, G. V. Jr.; Raines, G. A. 1993. Effects of the Chernobyl nuclear accident on utility share prices, Quarterly Journal of Business and Economics 32(2): 52-77.

Ramchander, S.; Schwebach, R. G.; Staking, K. 2012. The informational relevance of corporate social responsibility: evidence from DS400 index reconstitutions, Strategic Management 33(3): 303-314. http://dx.doi.org/10.1002/smj.952

Ramiah, V.; Cam, M. A.; Calabro, M.; Maher, D.; Ghafouri, S. 2010. Changes in equity returns and volatility across different Australian industries following the recent terrorist attacks, PacificBasin Finance Journal 18(1): 64-76. http://dx.doi.org/10.1016/j.pacfin.2009.07.001

Returns, P.; King, B. G.; Soule, S. A. 2007. Social movements as extra-institutional entrepreneurs: the effect of protests on stock, Administrative Science Quarterly 52(3): 413-442. 
Scholes, M.; Williams, J. 1977. Estimate betas from non-synchronous data, Journal of Financial Economics 5(3): 309-327. http://dx.doi.org/10.1016/0304-405X(77)90041-1

Strandskov, J. 2006. Sources of competitive advantages and business performance, Journal of Business Economics and Management 7(3): 119-129.

Wang, Y. H. 2009. Nonlinear neural network forecasting model for stock index option price: Hybrid GJR-GARCH approach, Expert Systems With Applications, 36(1): 564-570.

http://dx.doi.org/10.1016/j.eswa.2007.09.056

Wang, Y. H.; Chuang, C. C.; Lee, S. Y. 2010. Impact of compositions and characteristics of board of directors and earnings management on fraud, African Journal of Business Management 4(4): 496-511.

Wang, Y. H.; Shih, K. H.; Chuang, Y. H. 2010. Market behavior of patent infringement litigations, African Journal of Business Management 4(4): 390-395.

Yanase, N.; Yasuda, Y. 2010. The impact of the September 11 terrorist attack on the global insurance markets: evidence from the Japanese property-casualty insurance industry, Journal of Insurance Issues 33(1): 85-107.

Yang, F. J.; Wang, Y. H.; Chen, L. J. 2010. The information value of the infectious diseases outbreak on biotechnology, Journal of Medicinal Plants Research 4: 2103-2107.

Zhang, Y.; Dang, Y.; Chen, H.; Thurmond, M.; Larson, C. 2009. Automatic online news monitoring and classification for syndromic surveillance, Decision Support Systems 47(4): 508-517. http://dx.doi.org/10.1016/j.dss.2009.04.016

Yi-Hsien WANG, Dr, is Associate Professor of Department of Banking \& Finance, Chinese Culture University and holds Ph.D. in the Graduate School of Management, Ming Chuan University. His current research focus on Investment, Applied Economics, and Financial Time Series.

Fu-Ju YANG, Dr, is Professor of Department of Banking \& Finance, Chinese Culture University and holds Ph.D. in the Institute of Business \& Management, National Chiao Tung University. Her research interests focus on the Corporate Finance, Financial Management, and Investment Analysis and Management.

Li-Je CHEN is MBA student of Graduate Institute of International Business Administration, Chinese Culture University. His research interests include Investment, Corporate Finance, and Investment Analysis and Management. 